\title{
Hate is Such a Strong Word... Or is it? An Abstract
}

\author{
Aslı Kuşçu
}

\begin{abstract}
Emotions play an important role in consumer-brand relationships. Previous studies on consumer-brand relationships provide significant insights into strong and positive ones; nonetheless, there are also relationships on the other extreme, where consumers' negative perceptions towards some brands generate not only negative feelings but also destructive actions. Those were termed as brand dislike or brand avoidance in prior literature, with brand hate being the strongest. Hate is defined as "a deep, enduring, intense emotion expressing animosity, anger, and hostility toward a person, group, or object" (Reber 1985, p. 330). Consumer-brand relationships are believed to follow patterns that are identical to interpersonal relationships, where individuals are expected to build and continue affective bonds with brands (Aaker et al. 2004; Aggarwal 2004; Fournier 1998) that are primarily motivated by simple human instincts (Park et al. 2009) and interpersonal social norms (Gretry et al. 2017). Hence, very recent research on brand hate, relying on brand avoidance literature, demonstrated that individual perceptions and evaluations of brands' ideological misconduct and identity incongruence as well as negative experiences with the brand can lead to brand hate (Hegner et al. 2017; Zarantonello et al. 2018). Gregoire et al. (2009) further validated that individual-level differences such as perceived betrayal shape consumers' responses towards brands' actions; as it was validated for interpersonal relationships that it may not only worsen interactions and could push individuals further apart but also make people hate each other deeply (Fitness 2001). Relying on the previous literature, the current research suggests and tests the role of perceived betrayal in the transformation of passion into hate. Further, the consequences of hate were tested to advance knowledge on brand hate.
\end{abstract}

Keywords Hate $\cdot$ Emotion $\cdot$ Consumer brand relationships $\cdot$ Passion · Betrayal

References Available Upon Request

\footnotetext{
A. Kuşçu (凶)

Yeditepe University, Istanbul, Turkey

e-mail: asli.kuscu@yeditepe.edu.tr
}

F. Pantoja et al. (eds.), Enlightened Marketing in Challenging Times,

Developments in Marketing Science: Proceedings of the Academy of Marketing

Science, https://doi.org/10.1007/978-3-030-42545-6_99 